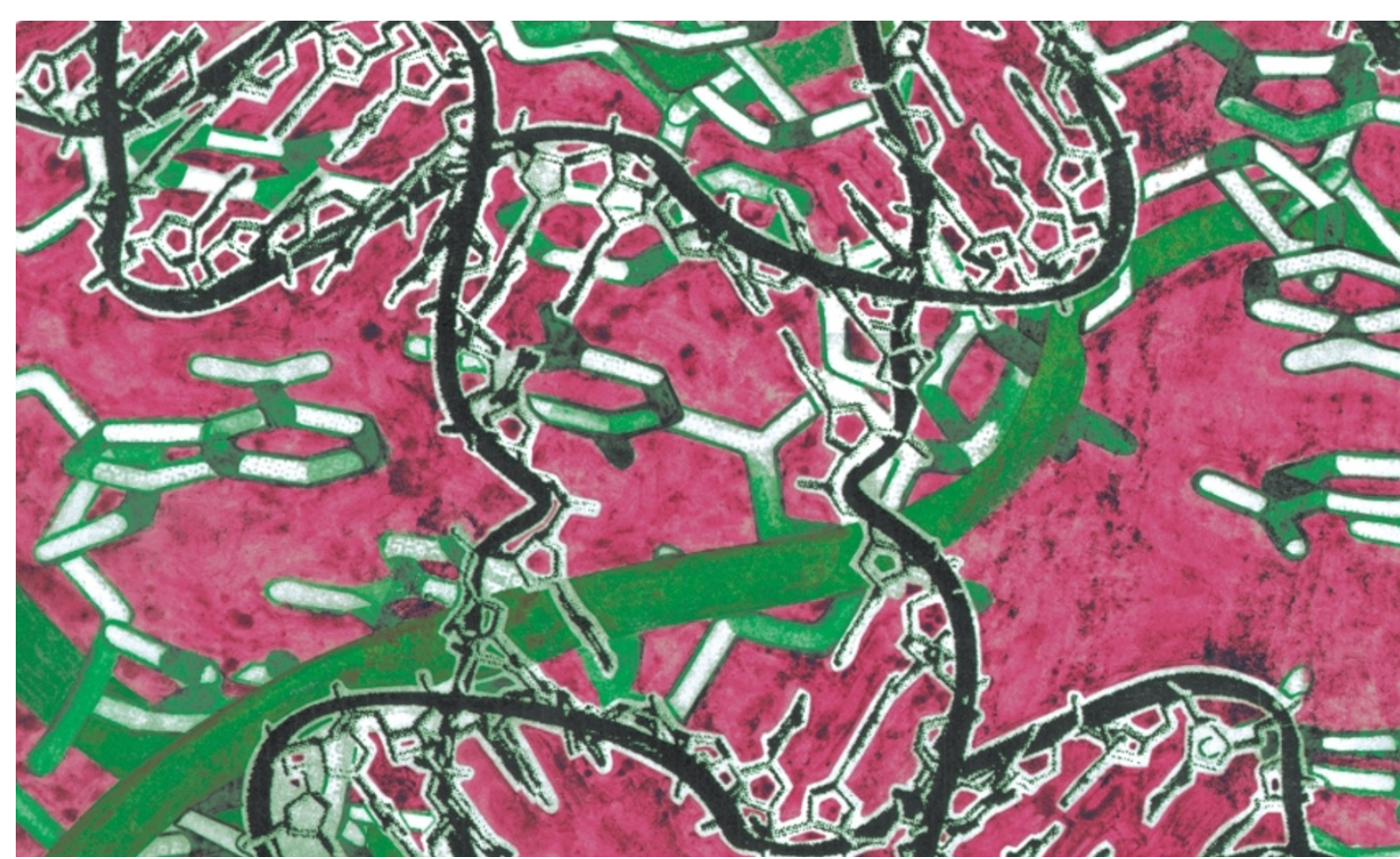

DNA REPLICATION

\section{New Year's resolution}

One resolution that's always broken is the conversion of Holliday junctions into linear duplex products. These four-stranded DNA crossover structures (see illustration), which are formed during DNA recombination and repair, are 'resolved' by the simultaneous introduction of breaks into two opposite strands. Several structure-specific endonucleases 'resolvases' - are known to do this job in prokaryotes, but similar activities have been surprisingly difficult to pin down in eukaryotic cells.

Enter MUS81. Two new papers show that this endonuclease is an essential component of a resolvase activity in fission yeast and human cells. What's more, MUS81 seems to have evolved specifically to cope with the problems caused by stalled replication forks.

Fission yeast mus81 was first described as a protein that associates with the replication checkpoint kinase cds1. It is related to the XPF subunit of the XPF-ERCC1 complex - a structure-specific endonuclease involved in nucleotide excision repair. Because XPF acts as part of a complex, Paul Russell and colleagues wondered whether the same might be true for mus81, and they report in Cell that it is.

Using two different approaches, Russell and co-workers identified eme1 (for 'essential meiotic endonuclease 1') as a new binding partner for mus81. Genetic analy- ses revealed that mus 81 and eme 1 act in the same pathway of resistance to UV damage, and that they are also required during meiosis. These studies indicated that the meiotic defect might be due to failure of the chromosomes to segregate properly, which could, in turn, be due to unresolved recombination intermediates — such as Holliday junctions.

To test this possibility, the authors expressed a bacterial Holliday junction resolvase called RusA in mus 81 mutants. This was enough to correct the meiotic defect in most cases, and it was dependent on the endonuclease activity of RusA. Consistent with this, the predicted endonuclease active site of mus 81 was found to be essential for activity.

Finally, Russell and colleagues used synthetic Holliday junctions (made by annealing oligonucleotides) to show that an affinity-purified mus81-eme1 complex acts as a resolvase in vitro. Like the previously characterized bacterial resolvases, mus81-eme1 introduces paired incisions on opposing strands of the $\mathrm{X}$ structure to form linear duplex products. However, unlike them, it cuts only $5^{\prime}$ to a double-strand/singlestrand junction - bacterial resolvases have no such requirement.

Russell's group next teamed up with Clare McGowan and co-workers to clone the human homologue of mus81. They report in Molecular Cell that, like the yeast protein, human MUS81 interacts with CDS1, a checkpoint kinase. Levels of MUS81 are increased in cells that are exposed to DNA-damaging agents ( $\gamma$-irradiation or UV) and to hydroxyurea, which interrupts DNA replication. Given that some UV-induced lesions are also thought to block progression of replication forks, the observed increase in MUS81 could, say the authors, indicate "a role in cellular responses to blocked DNA replication".

The authors next asked whether, like its yeast counterpart, MUS81 has a structure-specific endonuclease activity. They incubated synthetic junctions with MUS81 immunoprecipitates from HeLa cells, and observed the formation of defined cleavage products. The pattern of cleavage was consistent with the hypothesis that MUS81 cleaves on opposite strands, close to the doublestrand/single-strand junction. But as MUS81 elutes from a gel-filtration column at a higher molecular weight than the monomeric protein, the authors believe that it probably functions as a heterodimer. Identifying its partner - possibly a human eme1 homologue? - will be one of the next steps.

Alison Mitchel ORIGINAL RESEARCH PAPERS Boddy, M. N. et al. Mus81-Eme1 are essential components of a Holliday junction resolvase. Cell 107, 537-548 (2001) | Chen, X.-B. et al. Human Mus81associated endonuclease cleaves Holliday

junctions in vitro. Mol. Cell 8, 1117-1127 (2001) FURTHER READING Lilley, D. M. \& White, M. Th junction-resolving enzymes. Nature Rev. Mol. Cell

\section{WEB SITE}

Russell laboratory:

http://www.scripps.edu/mb/russell/
6.) References and links Biol. 2, 433-443 (2001)
H I G H LI G H T S

\section{IN THE NEWS}

To clone or not to clone? "Storm over human embryo" was the headline that greeted Advanced Cell Technology's (ACT) announcement that they had cloned the first human embryo (The Sun, 28 November 2001).

The study showed that human embryos could be developed by somatic cell transfer. The somatic nuclei showed evidence of reprogramming, returned to the pronuclear state and divided into six cells, like a normal fertilized human egg. Michael West, chief executive of ACT, stressed that the cloned embryo would be used for therapeutic reasons only, saying, "we took extreme measures to ensure that a human clone could not result from this technology" (The Guardian, 26 November 2001).

The response to this study was profound. John Gearhart, editorial advisor to the journal that published the study, resigned. The experiment, "was in his judgement a failure and should not have been published" (BBC News, 3 December 2001). The claim was vigorously defended by ACT.

But there were further ramifications from the research. The UK government rushed through legislation to close a legal loophole allowing people like Severino Antinori to carry out his attempts to help childless couples clone themselves. The European Commission said it opposed the research and would not finance any similar projects (BBC News, 26 November 2001).

However, the US Senate refused to ban human cloning research, as opponents stressed that the continuation of studies could lead to new disease treatments.

The Sun agreed, saying the benefits would outstrip the fears if we stay sensible. "Laws must be passed to stop full-scale cloning of a human being. Science is not evil. Neither are medical scientists. Indeed, many are unsung heroes".

Simon Frantz 